\title{
Migrating emboli of retinal arteries in thrombocythaemia
}

\author{
GUSTAV SINGER \\ Eye Department, Hospital ÚVN, Prague-Stresovice, Czechoslovakia
}

\section{Case report}

A 37-year-old man, in the early months of 1965 complained of repeated attacks of temporary blindness in the right eye, occurring on an average of three or four times a week, and lasting for 2 to 3 minutes.

\section{History}

The patient had had two cerebral concussions in $195^{2}$ and in 1955 . In $195^{8}$ he had a slight attack and in April, 1964, a more serious attack of aphasia. The neurological diagnosis was syndrome of the temporal lobe with aphasia, probably of vascular aetiology.

The visual acuity at this time was normal. On fundus examination a small white stripe was seen along the upper temporal branch of the right central retinal artery some 2 disc diameters from the edge of the papilla. This phenomenon was considered to be an arteriolar spasm. The surrounding retina showed an area of slight oedema I disc diameter in size. The patient had no symptoms. The oedema of the retina disappeared after 2 minutes as did the white stripe and the fundus became normal in appearance. Other clinical examinations were negative except for the neurological findings which consisted of the residue of expressive aphasia.

\section{Examination}

After discharge from hospital episodes of misty vision in the right eye occurred with greater frequency and the patient was re-admitted in December, 1965, when a photograph was taken of a spasm, this time progressing from the papilla to where the blood vessel divided into three branches above the papilla. This spasm remained visible for about half a minute (Fig. I) and at the same time

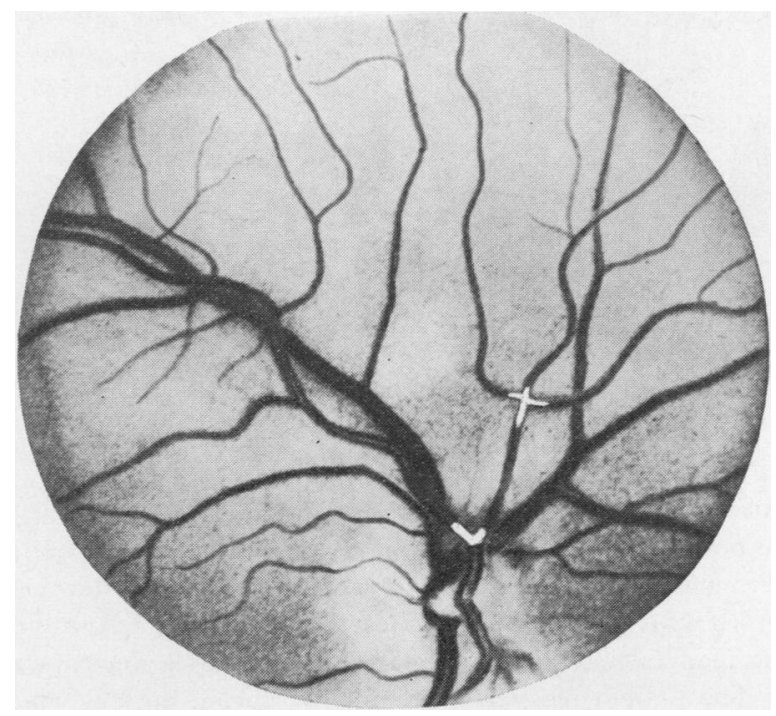

FIG. I Two emboli are seen, one at the bifurcation of the retinal artery, the other more distally 


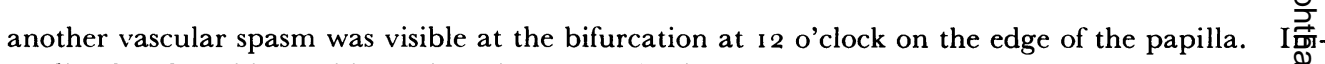
mediately after this a white stripe about one-third disc diameter long was observed in the up temporal branch of the central retinal artery, and this stripe moved slowly from the bifurcation at upper edge of the papilla towards the periphery (Figs 2 to 4). After about 2 minutes the fundis became normal in appearance.

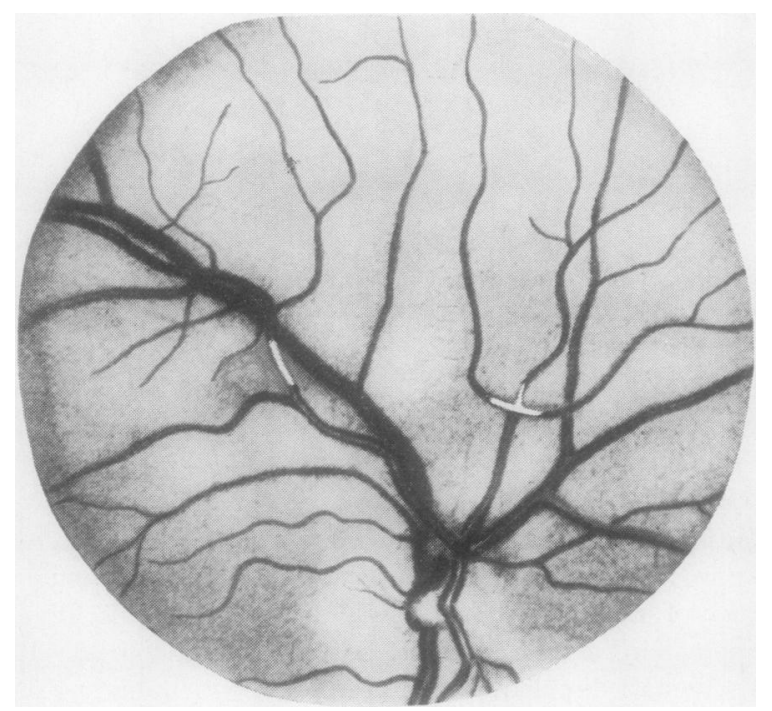

FIG. 2 The same emboli as in Fig. U़े

One is migrating to the temporal peripher

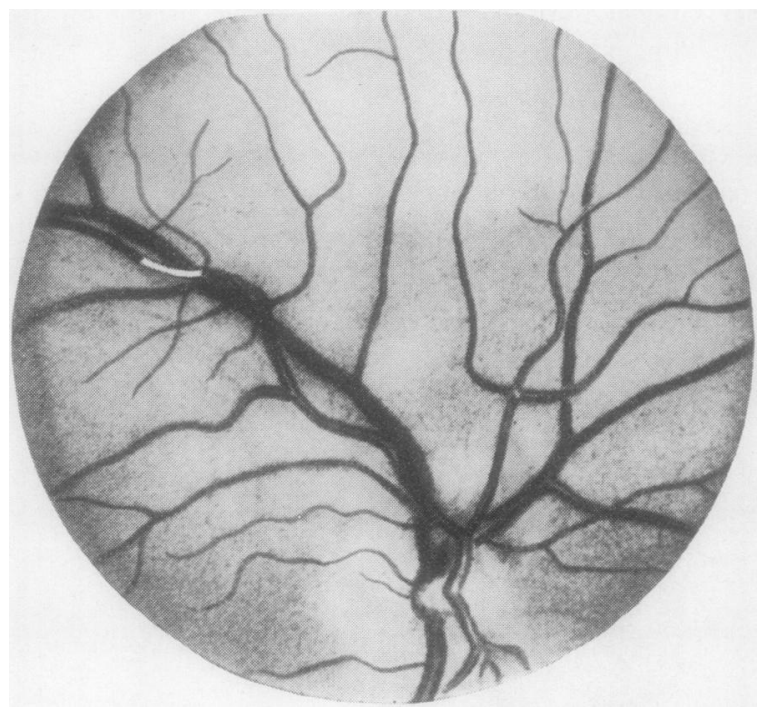

FIG. 3 Further migration of the term poral embolus seen in Fig. 2. The othe has disappeared peripherally

Progress

In spite of the use of vasodilators the patient's condition remained unchanged until January, i $9 \$ 96$, when he was admitted to the hospital's surgical department with suspected appendicitis. Several days after the removal of a chronically-inflamed appendix, a right hemiplegia developed and on A $_{\mathrm{e}}$ following day the patient's left leg was found to be cold and without a pulse. A thrombus, $12 \mathrm{~cm}$ 角 length, was removed from the iliac artery, but as gangrene of the left leg developed a below-k傋e amputation was performed. The patient recovered very slowly during the following months. 


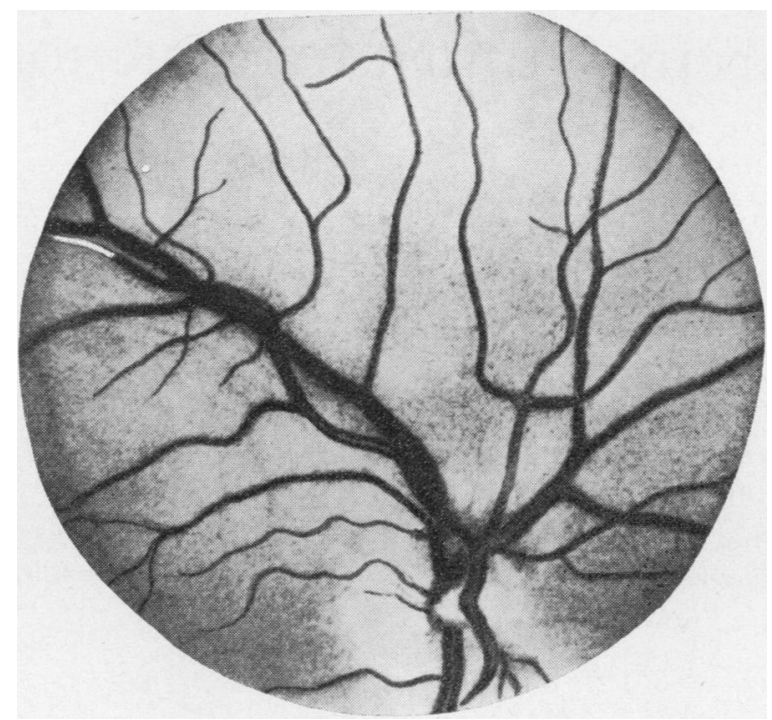

FIG. 4 The temporal embolus just before it disappeared peripherally

\section{Diagnosis}

In May, 1966, a routine blood count showed 1, 144,000 platelets per $\mathrm{cu} . \mathrm{cm}$. and a sternal puncture revealed large numbers of megakaryocytes in all stages of development confirming a diagnosis of essential thrombocythaemia.

\section{Treatment}

In view of these findings, treatment was commenced with the cytotoxic drug Mylecytan. After several weeks the number of platelets decreased to half a million. No visual disturbances have occurred since then.

\section{Comment}

It was concluded that this patient did not suffer from simple spasms of the retinal arteries but that the vascular occlusions were the result of so-called platelet-thrombi, which were producing the symptoms. Around these emboli the arterioles showed a spastic contraction.

That these emboli did not produce a permanent occlusion of the retinal arterioles may be due to the fact that, consisting of platelets, they are relatively soft and easily broken up.

Essential thrombocythaemia is a very rare disease. Lutz (1966) found only eighty cases of genuine essential thrombocythaemia. Most frequently repeated haemorrhage was cited as one of the symptoms, but one-third of all cases showed no haemorrhage at all, and the various symptoms of the patients were produced by some form of thromboembolic occlusions. It is assumed that the patient reported above belongs to this group.

Similar migrating emboli in the retinal arteries were described by Donaldson (1967) and Zweifach (1967), but not in patients with thrombocythaemia.

\section{Summary}

Migration of emboli in the retinal arteries is described and documented by photographs in a patient suffering from temporary blindness. The cause proved to be thrombocythaemia, and treatment with Mylecytan was followed by disappearance of the symptoms.

\section{References}

Donaldson, D. D. (1967) Arch. Ophthal. (Chicago), 78, 530

LUTZ, W. R. (1966) Schweiz. med. Wschr., 96, 1503

zWeifach, P. H. (1967) Arch. Ophthal. (Chicago), 78, 705 